\title{
Albuminaria Gravídica
}

Profesor Agregado: Santiago Lleras C. Jefe de Clinica: Guillermo Navas A. Interno: Pedro Cortes.

La albuminuria gravidica considerada hace tiempos como entidad definida dentro del grupo de las toxemias, partiendo del concepto, de muchos autores, de que el paso de las proteínas al través del epitelio renal de las embarazadas es un signo que hace parte del cuadro sintomático de las preeclampsias leves o graves, juzgamos conveniente que desaparezca de la nosología la denominación de "albuminuria gravidica" y que se incluya tan entidad en el grupo de las preeclampsias; ya que la albuminuria de la toxicosis tiene un valor clínico semejante a la cefálea, los edemas. la hematuria, etc.

El hallazgo de la albúmina en la orina de las embarazadas puede deberse a multitud de causas patológicas, no peculiares al estado grávido y entre ellas las afecciones crónicas o agudas del tracto urinario o puede ser ocasionado por este estado como es la preeclampsia leve o albuminuria gravídica y la preeclampsia grave o eclampsismo.

Traduce la albuminuria una baja reserva renal, ya que el riñón normal no da paso a las proteinas; relacionado este dato con la magnitud de los edemas, con los cambios tensionales, en especial de la misma, con la ntensidad de la cefálea, enn el estado cardiorrenal, con los trastornos, con el nitrógeno sanguineo no proteico, con las cifras de uricemia y colesterinemia, etc., tendremos una visión global de la nayor o menor gravedad del estado preeclámptico, si es que de él se trata y no de na afeccion intercurrente agravada por el embarazo.

Las consideraciones hechas anteriormente tienen como base la clasificación del Comité Americano de Bienestar Materno en la cual se consideran como enfermedades dependientes o auxiliares del estado gravidico, la preeclampsia leve o grave y la eclampsia convulsiva o no convulsiva.

Dieckmann añade a las anteriores, la enfermedad vásculo-renal, enfermedad hipertensiva. nefroesclerosis, glomerulonefritis aguda y eclampsia. Ninguno de los autores consultados anota en sus clasificaciones la albuminuria gravidida como enfermedad propia del embarazo, sino como un signo común a la preeclampsia y a la eclampsia.

Ordinariamente se aprecia en la preeclampsia que la relación existente entre la cantidad de albúmina excretada, los edemas, y la hipertensión es la siguiente: con albuminurias pequeñas de pocos centígramos, se aprecian edemas discretos y iunsiones diferenciales menores por aumento de la misma. Por el contrario cuando ios edemas son muy grandes, pudiendo llegar a la anasarca, se encuentran tensión arterial diferencial mayor y albuminuria más abundante. Estos son los tres signos principales del estado preeclámptico; los otros, trastornos visuales, cefáleas, tras- 
tornos hepáticos, aumento del peso corporal, manifestaciones nerviosas, traducen la intoxicación y completa el cuadro de los anteriores. Esta relación sintomática puede verse aiterada en los casos de albuminurias pequeñas con trastornos generales acentuados debido a un alto umbral de eliminación renal.

El resumen estadístico de los casos estudiados es el siguiente:

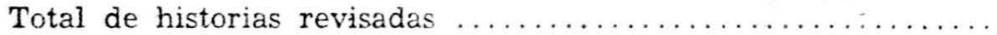

Albuminurias gravidicas . . . . . . . . . 137

Preeclampsias . . . . . . . . . . . . . . . . . . . . . . . . 622

Eclampsias .................................... 415

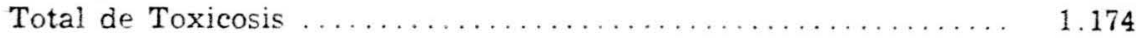

Frecuencia según las edades de las enfermas:

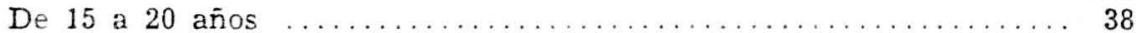

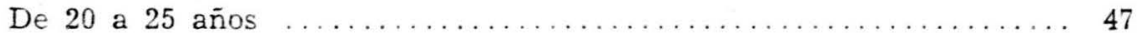

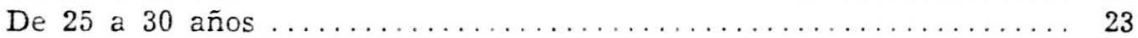

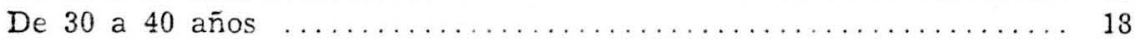

De más de 40 años ..................................... 8

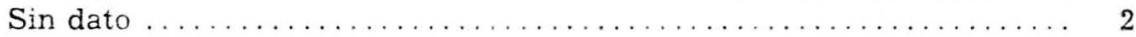

Frecuencia según el número de partos:

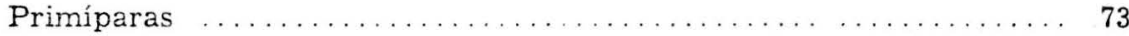

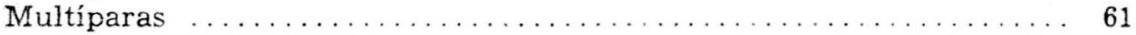

Frecuencia según la edad del embarazo:

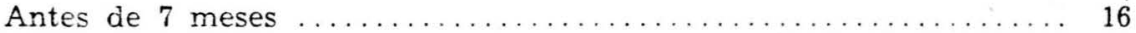

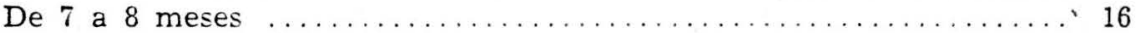

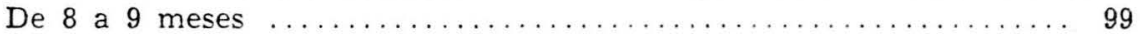

Frecuencia de los edemas:

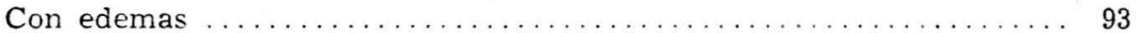

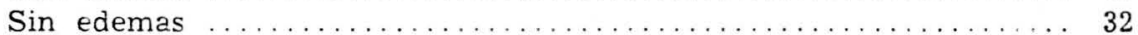

\section{Albuminurias:}

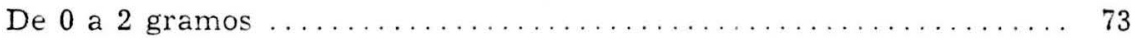

De 2 gramos en adelante ................................ 24

\section{Cilindruria:}

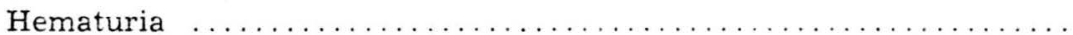

Estado del feto a la entrada al Servicio:

Feto vivo

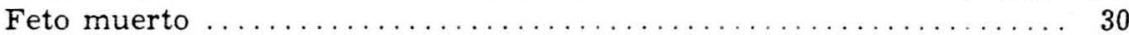

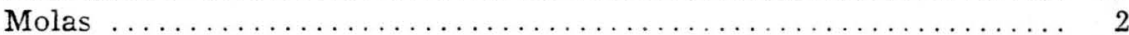

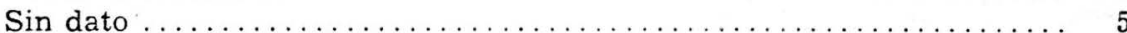

